\title{
An Experimental Study of Tool Wear and Cutting Force Variation in the End Milling of Inconel 718 with Coated Carbide Inserts
}

\author{
H.Z. Li ${ }^{*}$, H. Zeng, and X.Q. Chen \\ Singapore Institute of Manufacturing Technology \\ 71 Nanyang Drive, Singapore 638075
}

\begin{abstract}
Inconel 718 is a difficult-to-cut nickel-based superalloy commonly used in aerospace industry. This paper presents an experimental study of the tool wear propagation and cutting force variations in the end milling of Inconel 718 with coated carbide inserts. The experimental results showed that significant flank wear was the predominant failure mode affecting the tool life. The tool flank wear propagation in the up milling operations was more rapid than that in the down milling operations. The cutting force variation along with the tool wear propagation was also analysed. While the thermal effects could be a significant cause for the peak force variation within a single cutting pass, the tool wear propagation was believed to be responsible for the gradual increase of the mean peak force in successive cutting passes.
\end{abstract}

Keywords: tool wear; cutting force; end milling; Inconel 718; coated carbide insert; machining.

\section{INTRODUCTION}

The increasing demands for higher manufacturing efficiency have led to a great deal of researches aimed at machine tool condition monitoring. Among the indirect on-line tool wear monitoring methods, cutting force is the most commonly used variable as a tool wear indicator. Exploring the relationship between tool wear propagation and cutting force variation is of great importance to develop an effective tool condition monitoring strategy [1-4].

Inconel 718 is a nickel based superalloy which is widely used in aerospace industry. It contains a niobium (columbium) age-hardening addition that provides increased strength and corrosion resistance without decrease in ductility. The alloy has excellent creeprupture strength at temperature up to $700^{\circ} \mathrm{C}$. Therefore it is widely used in gas turbines, aircraft, rocket motors, spacecraft, nuclear reactors, etc. [5]. However, A high nickel alloy is well known as a difficult-to-cut material. Nickel alloys work harden rapidly. The high pressures produced during machining cause a hardening effect that makes further machining more difficult, and may also cause warping in small parts. Severe tool injury usually occurs in cutting this material. Rapid tool wear in machining has long been recognised as a challenging problem. Hence careful machining practices are a must, and it is necessary to develop an efficient on-line tool condition monitoring method [5-6].

\footnotetext{
* Corresponding author. Tel.: +65 6793 2375; fax: +65 6791 6377; e-mail: hzli@SIMTech.a-star.edu.sg
} 
Komanduri and Schroeder [6] investigated the shear instability and the deformation in chips produced in machining Inconel 718 at various speeds. Hanasaki et al. [5] studied the tool wear in turning of a high nickel alloy with four representative coated tools, and reported that in using coated tools, the flank groove wear was reduced and the tool life was determined by the boundary wear instead of the flank groove wear. Byrne and Bienia [7] found that TiN coated HSS was suitable for the machining of high nickel content soft magnetic materials from a tool life point of view although a large scatter in tool life occurred. Ezugwu et al. [8] investigated the performance of multiplayer-coated carbide tools in the turning of a martensitic stainless steel without coolant, and found that the predominant failure modes at higher speed conditions were significant nose wear and chipping/fracture of the cutting edge. In recent years, M. Alauddin et al. [9] studied the influence of the machining conditions on the average cutting forces in the end milling of Inconel 718 under dry conditions using uncoated carbide inserts, but the problems of tool wear were not addressed. E. -G. Ng et al. [10] studied the effects of cutter orientation, tool coating and cutting environment on tool life, tool wear mechanisms, cutting forces, chip formation, cutting temperature and workpiece surface roughness, during high speed ball nose end milling of Inconel 718.

Indexable coated carbide inserts are widely used in modern manufacturing industry. These inserts have one or more thin layers of wear resistance CVD or PVD coating such as TiC, TiN, Al2O3, ZrN, CrC or Diamond, which can improve machinability significantly. Today, "coated carbide grades for roughing and cermet for finishing" is a well established trend [11]. Unfortunately, limited work has been published regarding the performance of coated carbide inserts in milling superalloy materials. There is a need for further research into the tool wear behaviour of the coated carbide inserts and the cutting force variation in the end milling of superalloy materials such as Inconel 718. This paper presents an experimental study of end milling Inconel 718 with coated carbide inserts under dry cutting conditions. Both down milling and up milling operations were carried out. The tool wear propagation and cutting force variation along with it were analysed and discussed.

\section{METHODOLOGY}

\subsection{Experimental Setup}

Workpiece material: The workpiece material used in the machining test was Inconel 718. The workpieces were cut off from a warm-rolled Inconel bar, and their surfaces were prepared through face milling to get rid of the original skin layer containing hard particles like oxides or carbides. The dimension of the workpiece was $102 \mathrm{~mm} \times 50 \mathrm{~mm} \times 26 \mathrm{~mm}$. The Inconel 718 contains a significant amount of iron, niobium, and molybdenum along with lesser amount of aluminium and titanium. Its chemical composition confirms to the following specification

\begin{tabular}{|c|c|c|c|}
\hline $\mathrm{Ni}(+\mathrm{Co})$ & $50 \ldots 55 \%$ & $\mathrm{Cr}$ & $17 \ldots 21 \%$ \\
\hline $\mathrm{Fe}$ & rest & Co & $1 \%$ \\
\hline Mo & $2.8 \ldots 3.3 \%$ & $\mathrm{Nb}(+\mathrm{Ta})$ & $4.75 \ldots 5.5 \%$ \\
\hline $\mathrm{Ti}$ & $0.65 \ldots 1.15 \%$ & $\mathrm{Al}$ & $0.2 \ldots 0.8 \%$ \\
\hline
\end{tabular}




$\begin{array}{llllll}\mathrm{C} & : & 0.08 \% & \mathrm{Mn} & : & 0.35 \% \\ \mathrm{Si} & : & 0.35 \% & \mathrm{~B} & : & 0.006 \% \\ \mathrm{Cu} & : & 0.3 \% & & & \end{array}$

The nominal ultimate tensile strength of the material is $1240 \mathrm{MPa}$, and the nominal hardness is 36 HRC (355 HV10). However, it is noted that the measured hardness of the workpiece material was in a range from $433 \mathrm{HV} 10$ to $560 \mathrm{HV} 10$, where the variation of the hardness was up to roughly $30 \%$. This hardness variation might have been caused by the work hardening during the surface preparation of face milling, or by the manufacturing process of the material.

Cutting tool: The cutting tool used in the machining test was a Mitsubishi BAE500R161S16 end milling cutter with a F7030 coated carbide insert. The tool diameter was $16 \mathrm{~mm}$. Its axial rake was $2^{\circ}$, and its radial rake was $-8^{\circ}$. The insert had a cemented carbide substrate, with an inner coated layer of TiCN featuring spalling and wear resistance, a middle coated layer of $\mathrm{Al}_{2} \mathrm{O}_{3}$ featuring thermal stability and wear resistance, and an outer coated layer of TiN featuring low friction and welding resistance. The insert had a flat rake face. Its nose radius was $0.8 \mathrm{~mm}$. It covered a wide application range from ISO P10/M10 to ISO P30/M30 [11].

Machine tool: The machine tool used in the cutting test was a 3-axis vertical milling machine tool with a PC-based NC controller. The machine table could be moved in Cartesian coordinates in x, y-, and z-direction. A Kistler Type 9254 quartz 3-component dynamometer was mounted on the machine table to measure the cutting forces. The workpiece was mounted on the dynamometer through a specially designed fixture. The setup of the machining experiment is shown in Fig. 1.

\subsection{Experimental Procedure}

The machining tests were carried out in two types of end milling operations, i.e., down milling and up milling operations. The axial depth of cut $d_{a}$ was $1.2 \mathrm{~mm}$. The width of cut $w$ was $2 \mathrm{~mm}$. The feed per tooth $f_{t}$ was $0.03 \mathrm{~mm}$. The cutting speeds were $30 \mathrm{~m} / \mathrm{min}$ (spindle speed $n$ was $600 \mathrm{rpm}$ ) and $45 \mathrm{~m} / \mathrm{min}$ (spindle speed $n$ was $900 \mathrm{rpm}$ ). The feed direction of the workpiece was along the negative $\mathrm{x}$-axis as shown in Fig. 1, and the workpiece length in the feed direction $L$ was $50 \mathrm{~mm}$. Dry cutting was used for the experiment.

Therefore, the machining tests were divided into four groups: down milling with the spindle speed of $600 \mathrm{rpm}$, up milling with the spindle speed of $600 \mathrm{rpm}$, down milling with the spindle speed of $900 \mathrm{rpm}$, and up milling with the spindle speed of $900 \mathrm{rpm}$. In each group, two inserts were used to cut the workpiece in succession, and the flank wear of the inserts was measured after each cutting pass using a LEICA MZ12 microscopy system. The cutting forces were recorded down through a PC208AX Sony data recorder.

In down milling, maximum chip thickness occurs close to the point where the cutting tooth contacts the workpiece. As shown in Fig. 2, the entry angle of the tooth in the machining test of down milling operations, starting from the negative y-axis, should be 
$\varphi_{\text {entry }}=90^{\circ}+\arcsin \frac{r-w}{r}=90^{\circ}+\arcsin \frac{8-2}{8}=138.59^{\circ}$

The tooth exits the cutting at an exit angle approximately as $\varphi_{\text {exit }}=180^{\circ}$, and the chip thickness is zero at the exit point.

For up milling operation as shown in Fig. 3, the entry angle of the tooth is approximately $\varphi_{\text {entry }}^{\prime}=0^{\circ}$. The chip is very thin at the beginning where the tooth first contacts the work, and increases in thickness as the cutter rotates. It reaches the maximum when the tooth leaves the workpiece, where the exit angle is

$\varphi_{\text {exit }}^{\prime}=\arccos \frac{r-w}{r}=\arccos \frac{8-2}{8}=41.41^{\circ}$

Under the specified cutting condition, regardless down milling or up milling operations, the cutter starts cutting when it reaches a position where the distance from its centre to the workpiece edge perpendicular to the feeding direction is:

$$
L_{1}=\sqrt{r^{2}-(r-w)^{2}}=\sqrt{8^{2}-(8-2)^{2}}=5.29(\mathrm{~mm})
$$

It ends the cutting when its centre reaches the position of the other workpiece edge perpendicular to the feeding direction. Hence the machined length (ML) in one pass is

$$
M L=L+L_{1}=50+5.29=55.29(\mathrm{~mm})
$$

The number of impacts (cutting cycles) that an insert is subjected to in one cutting pass is

$$
N_{\text {imp }}=\frac{M L}{f_{t}}=\frac{55.29}{0.03}=1843
$$

When using the spindle speed $600 \mathrm{rpm}$, the cutting time in one cutting path is

$$
t_{1}=\frac{M L}{f_{t}} / \frac{n}{60}=\frac{55.29}{0.03} / \frac{600}{60}=184.3(\mathrm{~s})
$$

Similarly, for the spindle speed $900 \mathrm{rpm}$, the cutting time in one cutting path is

$$
t_{2}=\frac{M L}{f_{t}} / \frac{n}{60}=\frac{55.29}{0.03} / \frac{900}{60}=122.9 \text { (s) }
$$

During the machining tests, the instantaneous cutting force components in the $\mathrm{x}, \mathrm{y}$, and $\mathrm{z}$ directions, $F_{x}, F_{y}$, and $F_{z}$ as shown in Fig. 1, were measured using the three-component 
piezo dynamometer. The measured force components can be converted to the instantaneous cutting force components in the tangential, radial, and axial directions, i.e., $\mathrm{F}_{\mathrm{t}}, \mathrm{F}_{\mathrm{r}}, \mathrm{F}_{\mathrm{a}}$, using the following equations:

$$
\begin{aligned}
& F_{t}=F_{x} \cos \varphi+F_{y} \sin \varphi \\
& F_{r}=F_{x} \sin \varphi-F_{y} \cos \varphi \\
& F_{a}=F_{z}
\end{aligned}
$$

\section{RESULTS AND DISCUSSIONS}

\subsection{Propagation of Flank Wear}

The experimental results showed that the dominant tool wear and damage were flank wear and chipping. Damage observed on the rake surface, such as crater wear, was quite limited. The development of the flank wear of the coated carbide inserts used for both the down milling and the up milling under the spindle speed of $600 \mathrm{rpm}$ is shown in Fig. 4. There were six cutting passes performed for the down milling cases and four cutting passes performed for the up milling cases. Within these cutting passes performed, the wear propagation was almost linearly related to the cutting time for both the down milling and the up milling. For the cases of down milling, the width of flank wear was about $0.1 \mathrm{~mm}$ after the first cutting pass where the number of impacts for the insert was about 1843. After the sixth cutting path, the width of flank wear was about $0.3 \mathrm{~mm}$, as shown in Fig. 5. It can be seen from Fig. 5 that the worn surface was smooth. For up milling, the development of tool wear was more rapid compared with that for down milling. The width of flank wear was over $0.2 \mathrm{~mm}$ even after the first cutting pass. After the fourth cutting pass, it reached as high as $0.5 \mathrm{~mm}$, compared with the width of flank wear of only $0.19 \mathrm{~mm}-0.25 \mathrm{~mm}$ for the down milling cases after the same cutting pass. Fig. 6 shows a photograph of the flank wear after the fourth cutting pass of the up milling. It can be seen that the flank wear was quite severe, and there was also an obvious chipping mark on the flank face.

Fig. 7 shows the development of the flank wear of the coated carbide inserts under the spindle speed of $900 \mathrm{rpm}$ for both the down milling and the up milling operations. Seven cutting passes were performed for the down milling cases and five cutting passes were performed for the up milling cases. For the down milling cases, the width of flank wear was about $0.1-0.16 \mathrm{~mm}$ after the first cutting pass, and up to $0.4 \mathrm{~mm}$ after the seventh cutting pass. For the up milling cases, the width of flank wear was about $0.23 \mathrm{~mm}$ after the first cutting pass. It kept growing and reached $0.45 \mathrm{~mm}$ after the fifth cutting pass, whereas the width of flank wear in the down milling was only $0.37 \mathrm{~mm}$ after the same cutting pass. The wear propagation was also almost linearly related to the cutting time for both the down milling and the up milling within the cutting passes performed. The development of the flank wear in the up milling was also more rapid than that in the down milling. However, comparing with Fig. 4, it was noted that for the down milling cases, the wear propagation was quicker under the spindle speed of $900 \mathrm{rpm}$ than that of 
$600 \mathrm{rpm}$, whereas for the up milling cases, the wear propagation was a bit slower under the spindle speed of $900 \mathrm{rpm}$ than that of $600 \mathrm{rpm}$. Fig. 8 shows a photograph of the flank wear after the seventh cutting pass of the down milling, and Fig. 9 shows a photograph of the flank wear after the fifth cutting pass of the up milling. Chipping marks in the flank face can be found in both Fig. 8 and Fig. 9.

From the experimental results, it can be seen that the development of the flank tool wear was relatively rapid in general, and it was even worse for up milling. It is well known [12] that the curves that describe the flank wear versus the cutting time can be divided into three different regions as shown in Fig. 10. The first region is for the break-in-period where the flank wear initially increases rapidly and later-on gradually reduces to a constant rate. During this period, the wear behaves in the form of an exponential curve. The second region is the steady state wear region in which the wear curve can be regarded as linear to the cutting time. The third region is the failure region in which different wear curves can be observed when different groups of tool-workpiece materials are machined. In the end milling of Inconel 718 with coated carbide inserts studied here, the break-in-period was not explicit in the curve of flank wear versus cutting time. It can be concluded that this period was very short and occurred in the early phase of the first cutting pass for each new insert. The flank wear curves as shown in Fig. 4 and Fig. 7 can be regarded as falling into the second region. The wear rate was almost constant until a total tool failure was reached, and there was no obvious transition from the second region to the third region.

Milling is characterised with an interrupted cutting action where each tooth produces a chip of variable thickness. The cutting circumstances are more adverse than that in turning. Since Nickel alloys work harden rapidly, once the milling cutter starts cutting, it will become more and more difficult for further machining due to the hardening effect. When the cutting edge is not sharp enough, the metal is pushed instead of cut. This will result in higher cutting force and higher temperature. For the coated carbide insert in the milling cutter, although the multiple coating layers can improve wear resistance significantly, it is still hard to bear the high load impacts and high temperature. Actually the coated layer cannot stand for long before it is worn. This will result in severe tool wear and short tool life. In the up milling operations, the cutter encounters minimum chip thickness as it enters the workpiece. This approximating rubbing at the beginning of the cut will cause an excessively work hardened layer in the workpiece, therefore higher cutting forces, higher tool wear rate and shorter tool life than those in down milling were observed. It is recommended that down milling operations be used as far as possible.

\subsection{Cutting Force Variation}

The cutting force waveforms in the first cutting pass of down milling under the spindle speed of $600 \mathrm{rpm}$ are shown in Fig. 11. The major cutting force component was in the positive $\mathrm{Y}$ direction, while the peak cutting force component in the negative $\mathrm{X}$ direction was less than half of that in the Y direction. At the initial stage when the cutter was fully engaged in cutting, there were peak cutting force components in both positive and negative $\mathrm{Z}$ directions. Along with the progress in the cutting pass, there was a significant increase of the peak force component in the positive $\mathrm{Z}$ direction, which was from $80 \mathrm{~N}$ to 
$218 \mathrm{~N}$. On the other hand, the peak force component in the negative Z direction decreased to a very low level. The peak force components in the negative $\mathrm{X}$ and the positive $\mathrm{Y}$ directions also underwent slight hikes.

The cutting force waveforms in the second and the sixth cutting pass of down milling under the spindle speed of 600 rpm are shown in Fig. 12 and Fig. 13 respectively. Fig. 14 illustrates the variation of the peak cutting force components in the three directions for the six cutting passes. The maximum peak value, the minimum peak value, as well as the mean peak value for each cutting pass were designated in the figure. It is clear that for each pass, the peak values kept up a steady increase within a certain range. There existed overlaps of the force variation ranges between successive cutting passes. Along with the tool wear propagation, increasing of the mean peak values in the $\mathrm{X}, \mathrm{Y}$, and $\mathrm{Z}$ directions was a general trend. Nevertheless, it was also noted from the comparison between the fifth cutting pass and the sixth cutting pass that although the mean peak continued to increase in the $\mathrm{X}$ direction, the mean peak decreased slightly in the $\mathrm{Y}$ and $\mathrm{Z}$ directions in the sixth cutting pass.

The cutting force waveforms in the first cutting pass of up milling under the spindle speed of 600 rpm are shown in Fig. 15. The waveform pattern shows significant difference compared with that of down milling in Fig. 11. The major cutting force component was in the positive $\mathrm{X}$ direction, with a peak value of about $400 \mathrm{~N}$. The axial cutting force component was in the positive $\mathrm{Z}$ direction with close amplitude as in the $\mathrm{X}$ direction. The peak force component in the negative $Y$ direction was about $270 \mathrm{~N}$, nearly two third of the peak value in the $X$ direction. It can be seen that the resultant cutting force in up milling was larger than that in down milling. During one cutting pass, the peak force in the $\mathrm{Z}$ direction went through constant increasing, and the peak force in the $\mathrm{X}$ direction also increased slightly. However, the variation of the peak force in the negative $Y$ direction was not so regular. Both increasing and decreasing were observed in the same pass. The cutting force waveforms in the second cutting pass and the fourth cutting pass of up milling under the spindle speed of 600 rpm are shown in Fig. 16 and Fig. 17 respectively. Fig. 18 summarises the variation of the peak cutting force components in the three directions for the four cutting passes. It was found that along with the development of the tool wear, there were irregular variation trends of the cutting force peaks during one cutting pass, especially for the fourth cutting pass as in Fig. 17. Nevertheless, the overall trend of the mean peak values in the $\mathrm{X}, \mathrm{Y}$, and $\mathrm{Z}$ directions was a steady increase along with the tool wear propagation in successive cutting passes.

Fig. 19 and Fig. 20 show the variation of the peak cutting force components in the three directions along with the cutting passes for the down and up milling operations respectively under the spindle speed of $900 \mathrm{rpm}$. It is evident that the overall trend of the mean force peak value in Fig. 19 for down milling under $900 \mathrm{rpm}$ is similar to that in Fig. 14 for down milling under 600 rpm, and the variation of peak cutting force in Fig. 20 for up milling under $900 \mathrm{rpm}$ is also similar to that of Fig. 18 for up milling under $600 \mathrm{rpm}$.

The variation of the peak cutting force components could be attributed to a number of possible factors, such as the development of the tool wear, the work harden of the 
workpiece material, the temperature change in the tool-workpiece interface, and the thermal expansion of the cutting tool and workpiece. It is believed that the thermal effects could be a significant cause for the peak force variation within a single cutting pass, and that the tool wear propagation was the major reason for the gradual increase of the mean peak force in successive cutting passes. In the on-line tool condition monitoring, although the peak force component in the $\mathrm{X}$ and $\mathrm{Y}$ directions could be used as the main tool wear indicator, attention must be paid to the wide variation range of the peak force components during one cutting pass.

\section{CONCLUSIONS}

(1) The experimental study of end milling Inconel 718 using coated carbide inserts under dry cutting conditions showed that significant flank wear was the predominant failure mode affecting tool performance and tool life. The tool flank wear propagation in the up milling operations was more rapid than that in the down milling operations.

(2) The variation of the peak cutting force components was analysed. It was found that for each cutting pass, the peak values of the cutting force components showed a steady increase within a certain range. The force variation ranges overlapped between successive cutting passes. Along with the tool wear propagation in successive cutting passes, the overall trend of the mean peak values in the $\mathrm{X}, \mathrm{Y}$, and $\mathrm{Z}$ directions for both the down and up milling operations was in a gradual increase.

(3) The variation of the peak cutting force components could be attributed to a number of possible factors. It is believed that the thermal effects could be a significant cause for the peak force variation within a single cutting pass, while the tool wear propagation was the major reason for the gradual increase of the mean peak force in successive cutting passes. The relationship between tool wear propagation and cutting force variation can be used to develop effective tool condition monitoring strategies.

\section{ACKNOWLEDGMENTS}

This research is supported by the Agency For Science, Technology And Research (A*STAR) of Singapore with project No. I01-A- 012.

\section{REFERENCES}

[1] A.M. Fong, X.Q. Chen, H.Z. Li, Overview of Material Processing Automation, in: X.Q. Chen, R. Devanathan, A. M. Feng (Eds.), Advanced Automation Techniques in Adaptive Material Processing, World Scientific Publishing Co. Pte. Ltd., 2002, pp. 1-18. [2] H.Z. Li, X.Q. Chen, H. Zeng, Flank Wear of Coated Carbide Inserts in the End Milling of Inconel 718, Proceedings of International Conference on Precision Engineering (IcoPE2003/04), March 2-5, 2004, Grand Hyatt Singapore, Pp. 203-209.

[3] P.W. Prickett, C. Johns, An Overview of approaches to end milling tool monitoring, International Journal of Machine Tools \& Manufacture. 39 (1999) 105-122. 
[4] G. Byrne, D. Dorfield, I. Inasaki, G. Ketteler, W. König, R. Teti, Tool condition monitoring (TCM) - the status of research and industrial application, Annals of the CIRP, 44/2 (1995) 541-567.

[5] S. Hanasaki, J. Fujiwara, M. Touge, Tool wear of coated tools when machining a high nickel alloy, Annals of the CIRP, 39/1 (1990) 77-80.

[6] R. Komanduri, T. A. Schroeder, On shear instability in machining a Nickel-Iron base superalloy, ASME Journal of Engineering for Industry, 108 (1986) 93-100.

[7] G. Byrne, B. Bienia, Tool life scatter when milling with TiN-coated HSS indexible inserts, Annals of the CIRP, 40/1 (1991) 45-48.

[8] E. O. Ezugwu, K. A. Olajire, A. Jawaid, Wear performance of multiplayer-coated carbide tools, Machining Science and Technology, 5/1 (2001) 115-119.

[9] M. Alauddin, M.A. Mazid, M.A. El Baradi, M.J.S. Hashmi, Cutting forces in the end milling of Inconel 718, Journal of Materials Processing Technology, 77 (1998) 153159.

[10] E. -G. Ng, D. W. Lee, A. R. C. Sharman, R. C. Dewes, D. K. Aspinwall, High speed ball nose end milling of Inconel 718, Annals of the CIRP, 49/1 (2000) 41-46.

[11] Mitsubishi carbide catalogue CB005: Metal Cutting Carbide Tools. Mitsubishi Materials Corporation, 2001-2002.

[12] A. Ber, S. Kaldor, The first second of cutting, wear behaviour, Annals of the CIRP, 31/1 (1982) 13-17. 


\section{LIST OF FIGURES}

Figure 1. Experimental setup

Figure 2. Down milling

Figure 3. Up milling

Figure 4. Development of flank wear under $600 \mathrm{rpm}$

Figure 5. Flank wear of the insert after the sixth pass of down milling under $600 \mathrm{rpm}$

Figure 6. Flank wear of the insert after the fourth pass of up milling under $600 \mathrm{rpm}$

Figure 7. Development of flank wear under $900 \mathrm{rpm}$

Figure 8. Flank wear of the insert after the seventh pass of down milling under $900 \mathrm{rpm}$

Figure 9. Flank wear of the insert after the fifth pass of up milling under $900 \mathrm{rpm}$

Figure 10. Typical curve of flank wear versus cutting time

Figure 11. Cutting force waveforms in the first pass of down milling under $600 \mathrm{rpm}$

Figure 12. Cutting force waveforms in the second pass of down milling under $600 \mathrm{rpm}$

Figure 13. Cutting force waveforms in the sixth pass of down milling under $600 \mathrm{rpm}$

Figure 14. Variation of peak cutting force in (a). X, (b). Y, and (c). Z directions, down milling, $600 \mathrm{rpm}$

Figure 15. Cutting force waveforms in the first pass of up milling under $600 \mathrm{rpm}$

Figure 16. Cutting force waveforms in the second pass of up milling under $600 \mathrm{rpm}$

Figure 17. Cutting force waveforms in the fourth pass of up milling under $600 \mathrm{rpm}$

Figure 18. Variation of peak cutting force in (a). X, (b). Y, and (c). Z directions, up milling, $600 \mathrm{rpm}$

Figure 19. Variation of peak cutting force in (a). X, (b). Y, and (c). Z directions, down milling, $900 \mathrm{rpm}$

Figure 20. Variation of peak cutting force in (a). X, (b). Y, and (c). Z directions, up milling, 900 rpm 


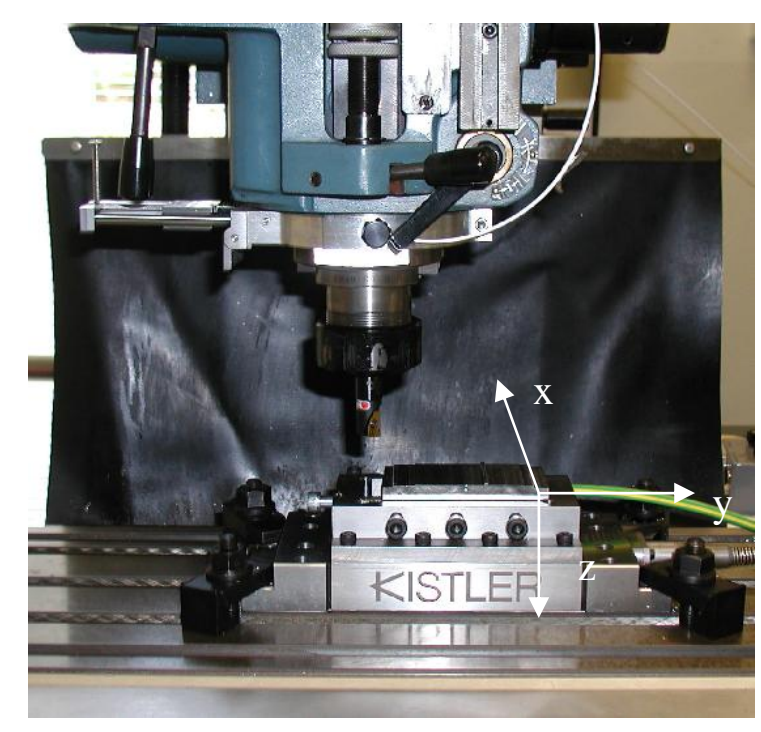

Figure 1. Experimental setup

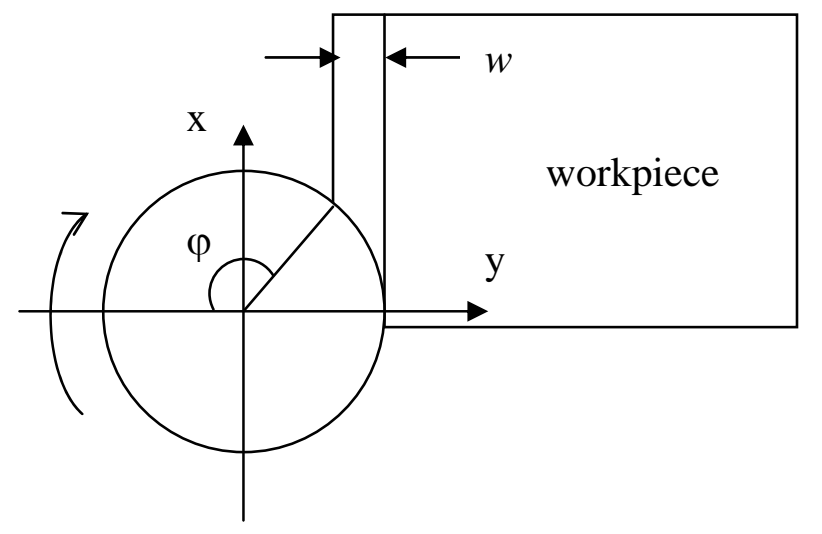

Figure 2. Down milling

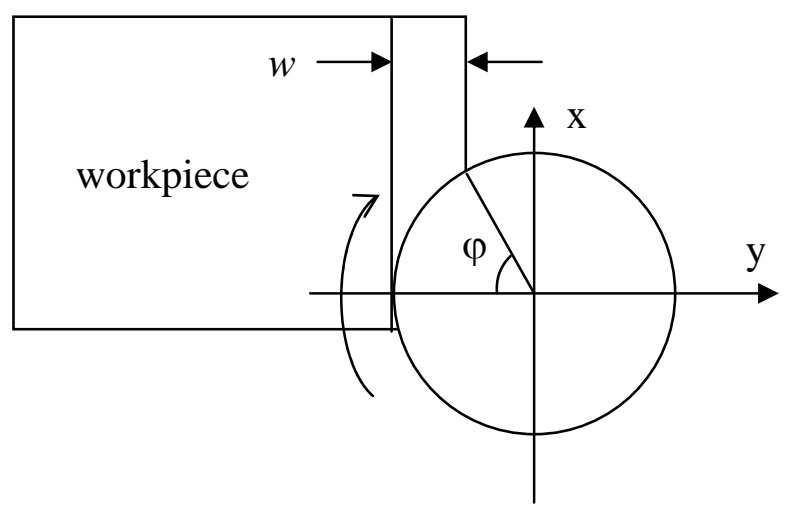

Figure 3. Up milling 
$\longrightarrow$ Dow $n$ milling, insert $1 \longrightarrow$ Dow $n$ milling, insert 2

$\neg$ Up milling, insert $1 \longrightarrow$ Up milling, insert 2

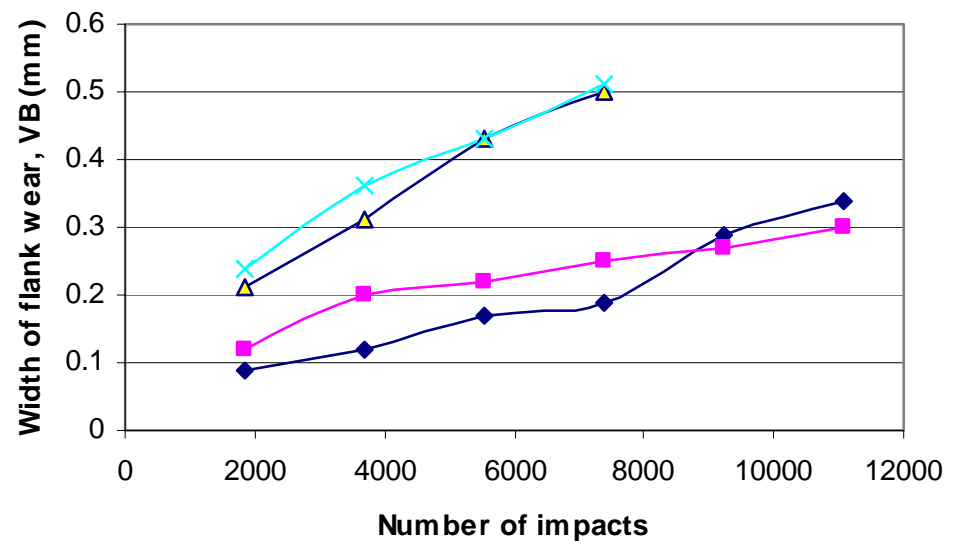

Figure 4. Development of flank wear under 600 rpm

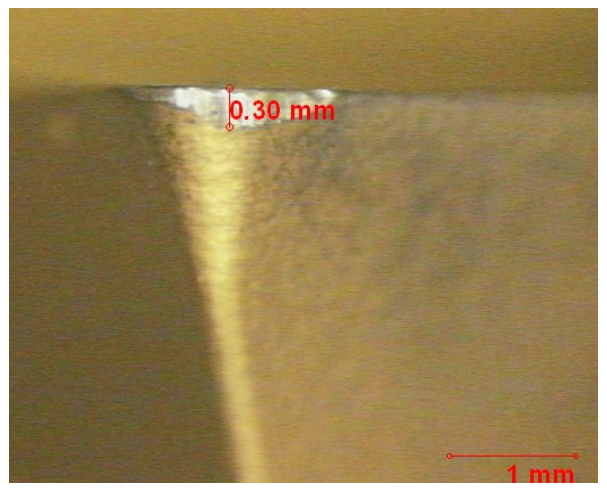

Figure 5. Flank wear of the insert after the sixth pass of down milling under $600 \mathrm{rpm}$ 


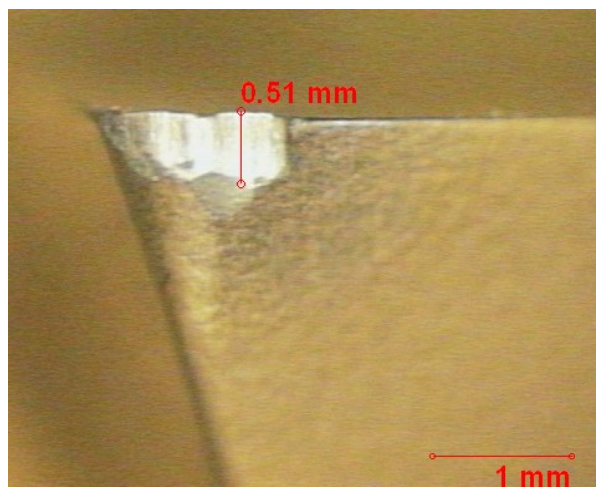

Figure 6. Flank wear of the insert after the fourth pass of up milling under $600 \mathrm{rpm}$

$\longrightarrow$ Dow $n$ milling, insert $1 \longrightarrow$ Dow $n$ milling, insert 2

$\neg \longleftarrow$ Up milling, insert $1 \longrightarrow$ Up milling, insert 2

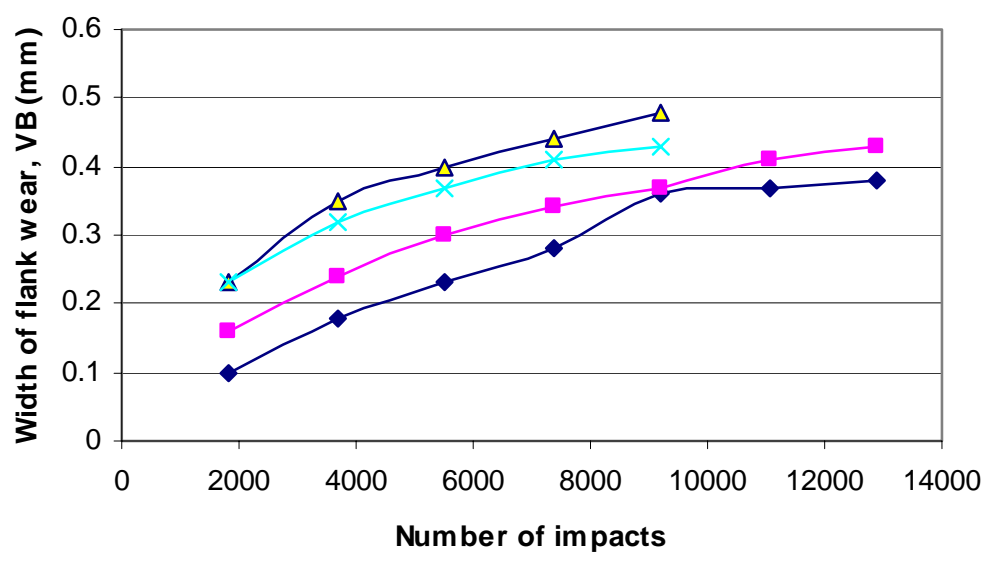

Figure 7. Development of flank wear under 900 rpm 


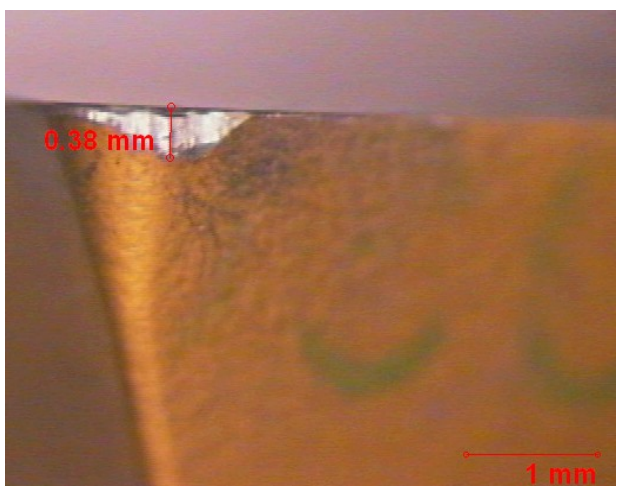

Figure 8. Flank wear of the insert after the seventh pass of down milling under $900 \mathrm{rpm}$

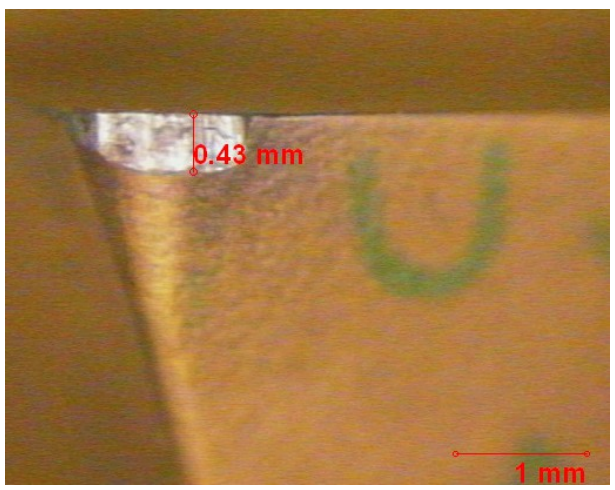

Figure 9. Flank wear of the insert after the fifth pass of up milling under $900 \mathrm{rpm}$

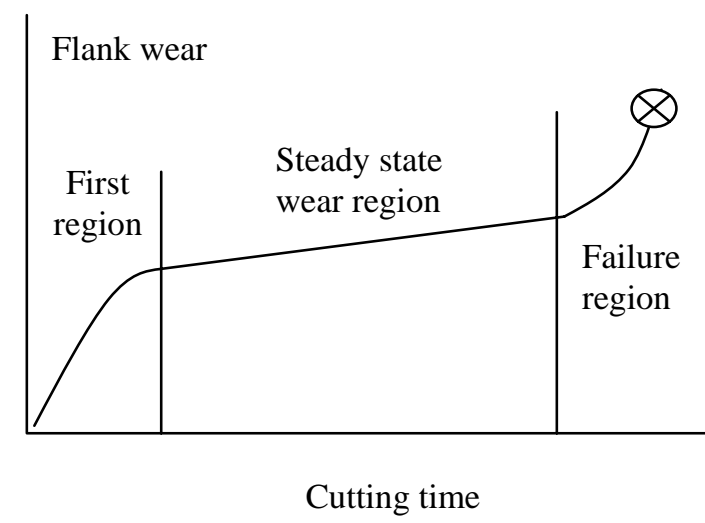

Figure 10. Typical curve of flank wear versus cutting time 

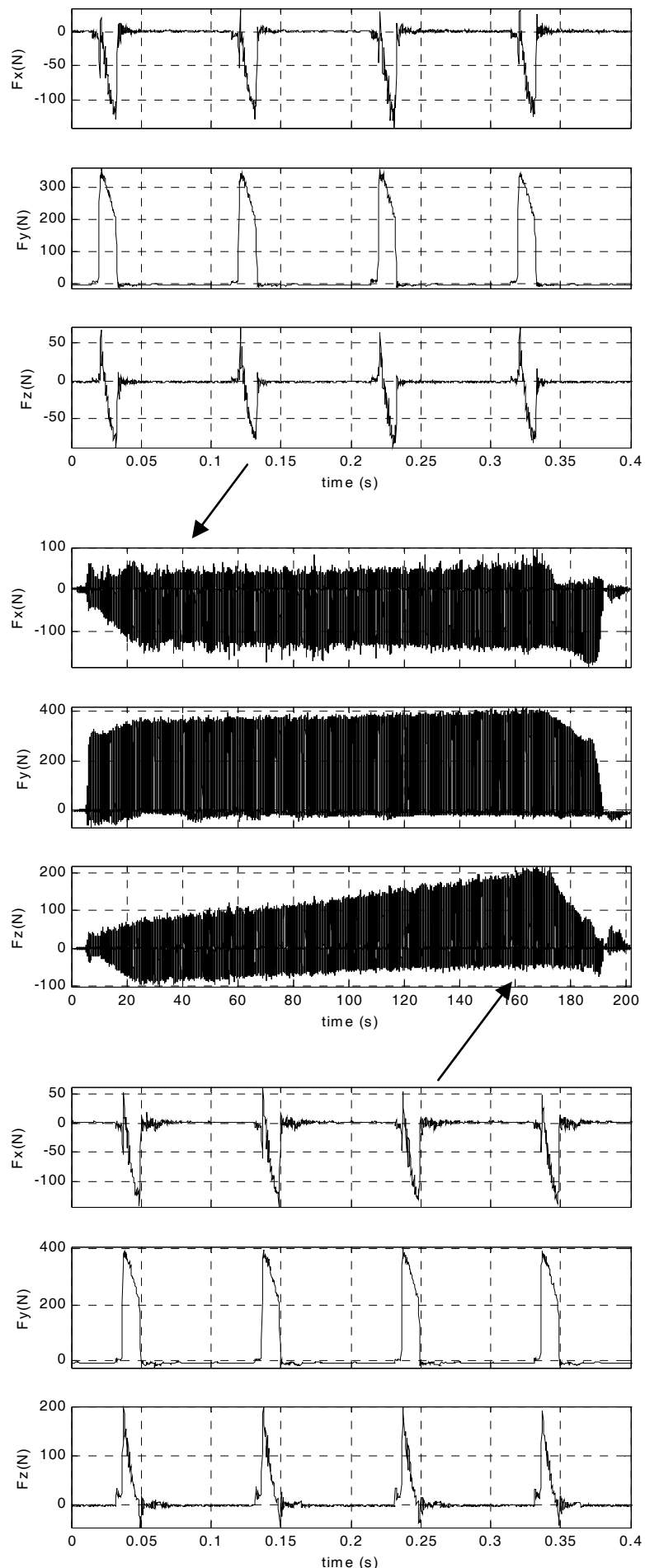

Figure 11. Cutting force waveforms in the first pass of down milling under $600 \mathrm{rpm}$ 

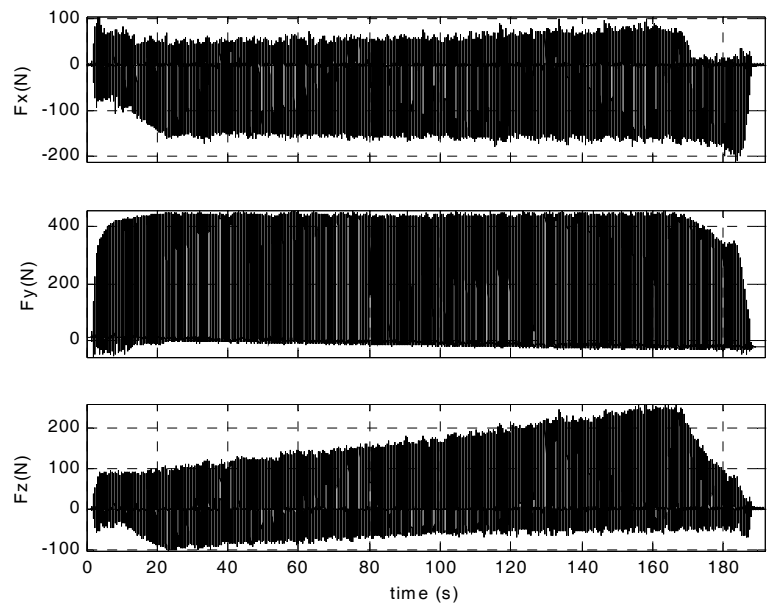

Figure 12. Cutting force waveforms in the second pass of down milling under $600 \mathrm{rpm}$
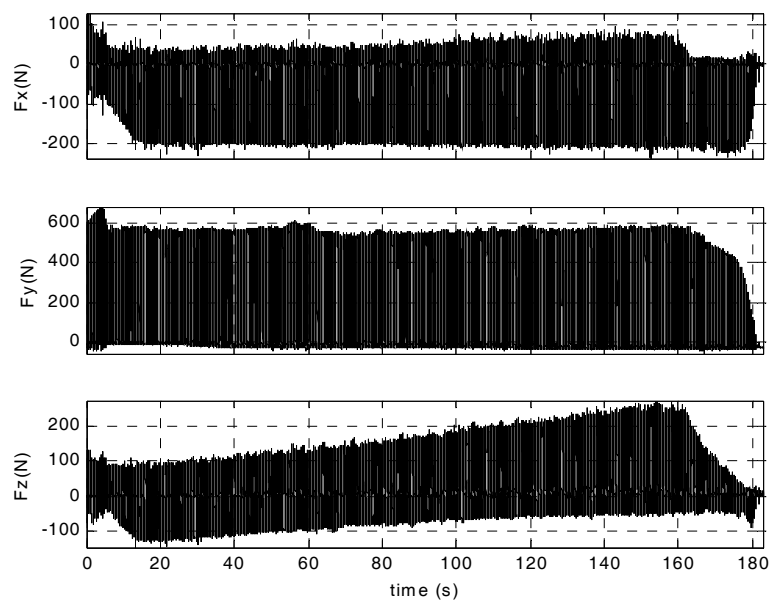

Figure 13. Cutting force waveforms in the sixth pass of down milling under $600 \mathrm{rpm}$ 


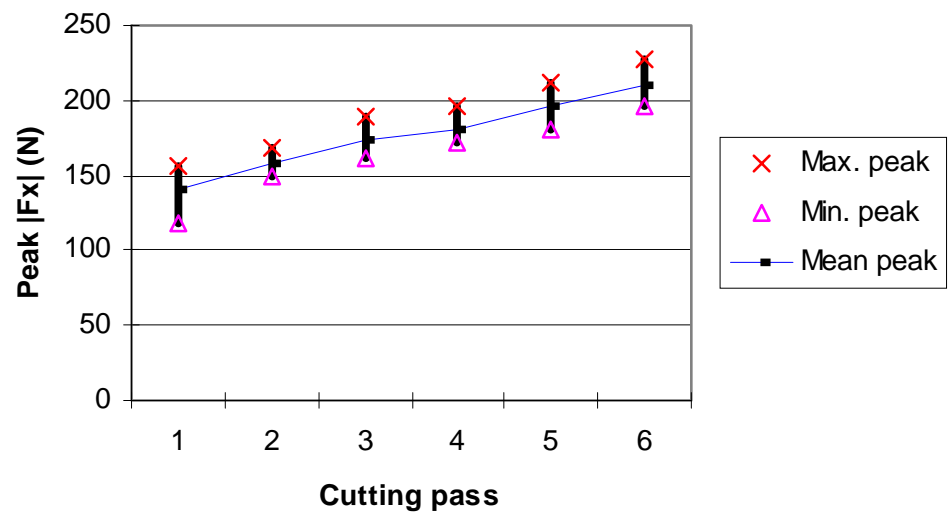

(a)

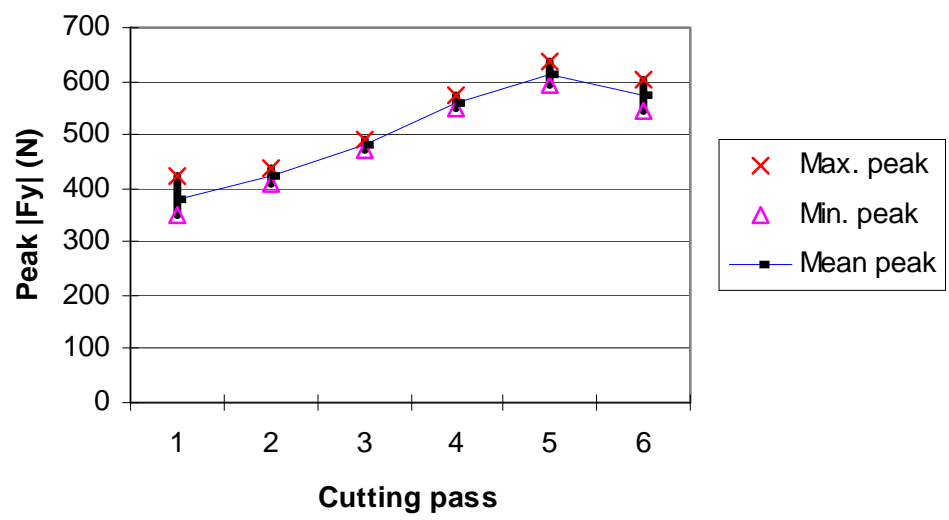

(b)

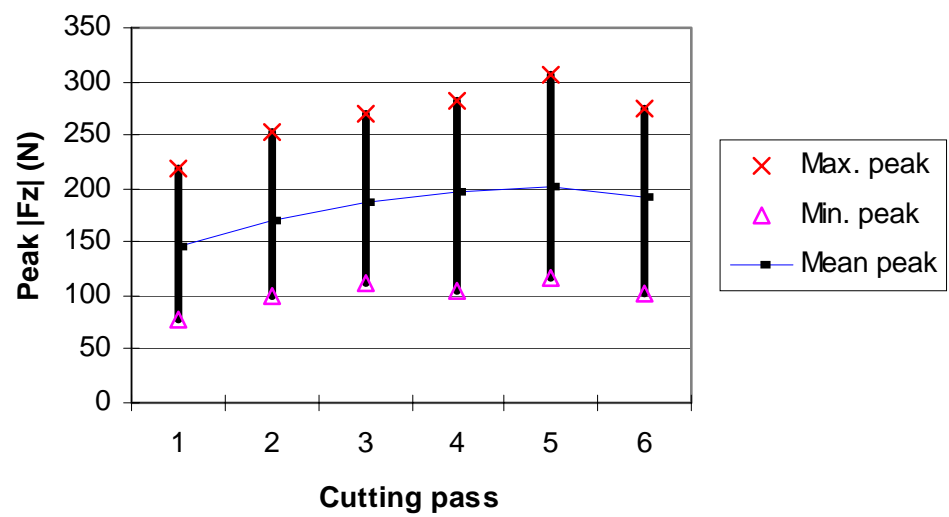

(c)

Figure 14. Variation of peak cutting force in (a). X, (b). Y, and (c). Z directions, down milling, 600 rpm 

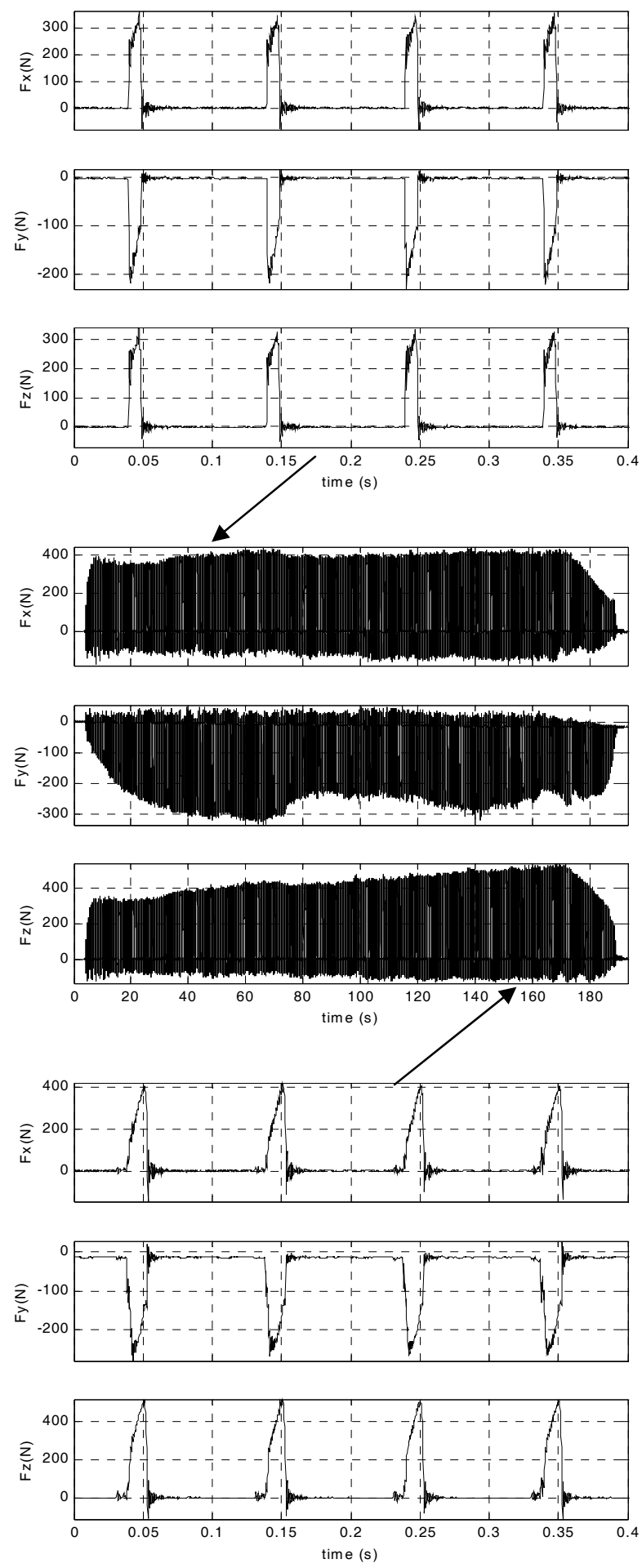

Figure 15. Cutting force waveforms in the first pass of up milling under $600 \mathrm{rpm}$ 

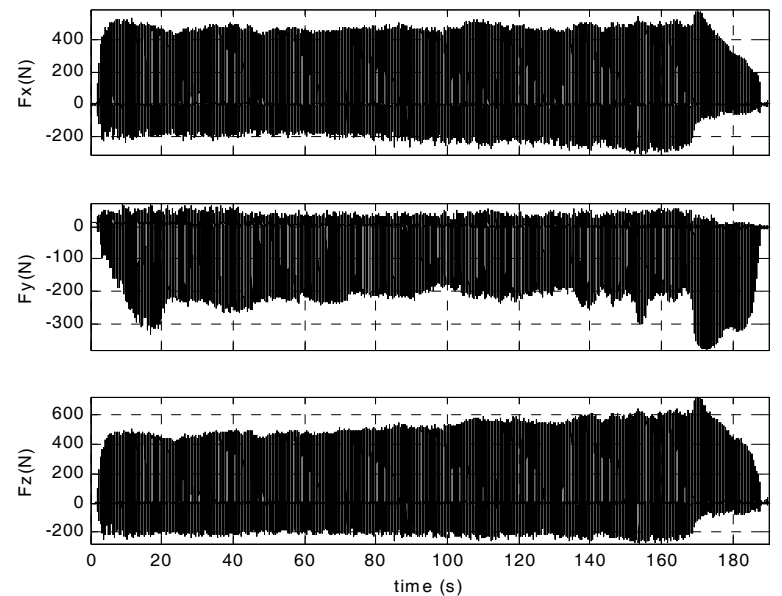

Figure 16. Cutting force waveforms in the second pass of up milling under $600 \mathrm{rpm}$
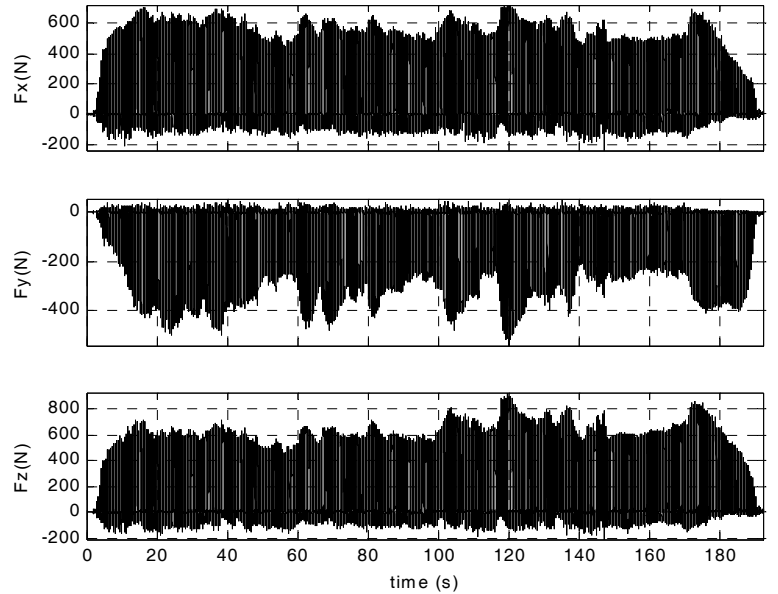

Figure 17. Cutting force waveforms in the fourth pass of up milling under $600 \mathrm{rpm}$ 


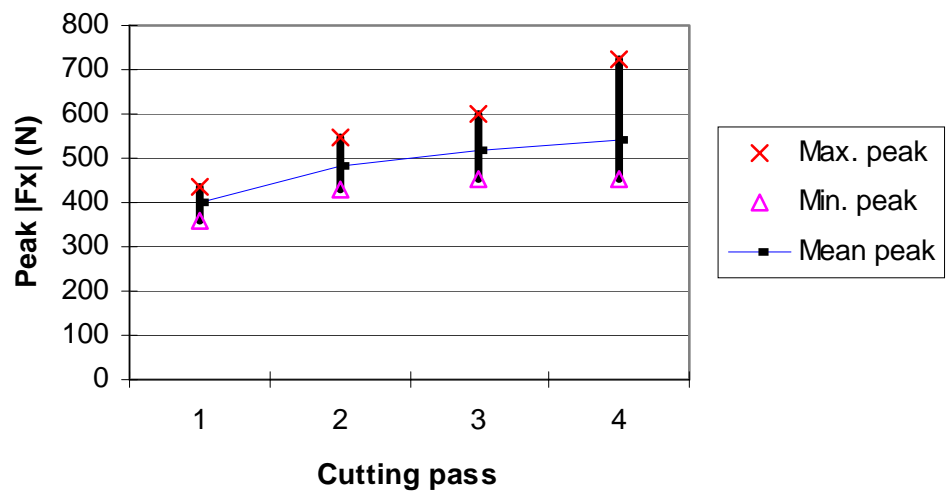

(a)

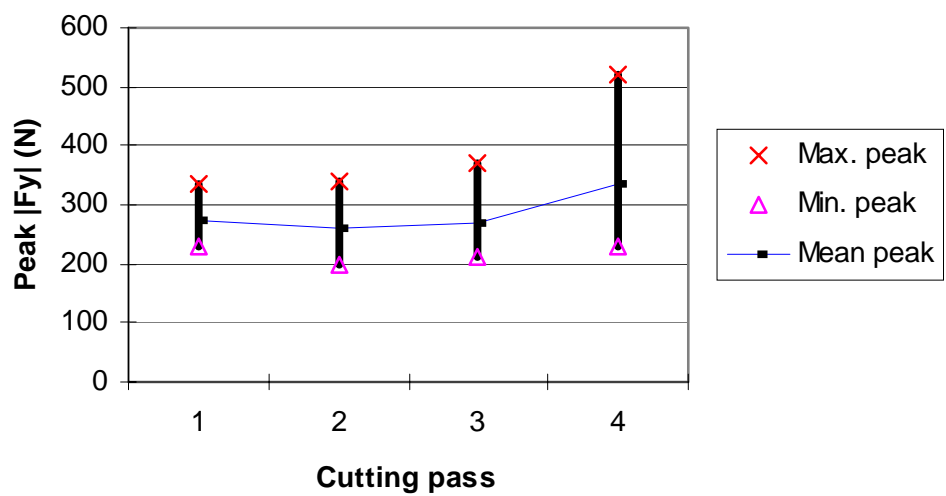

(b)

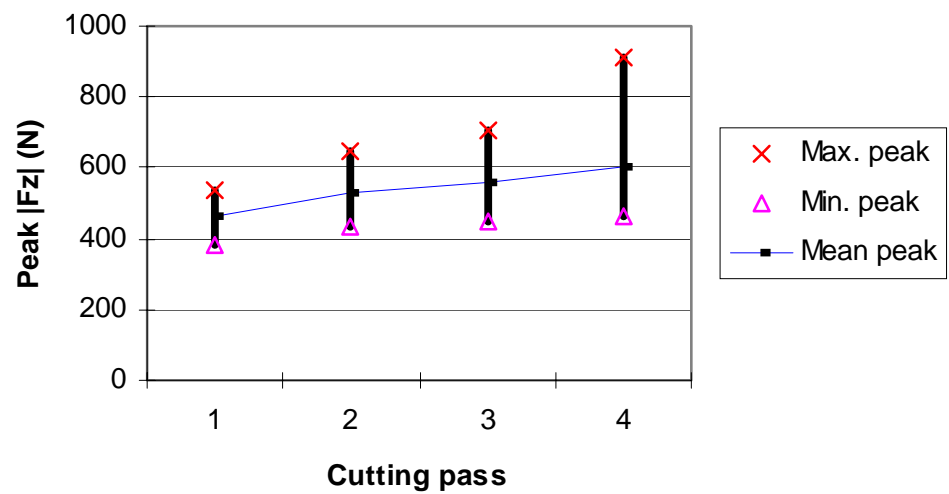

(c)

Figure 18. Variation of peak cutting force in (a). X, (b). Y, and (c). Z directions, up milling, $600 \mathrm{rpm}$ 


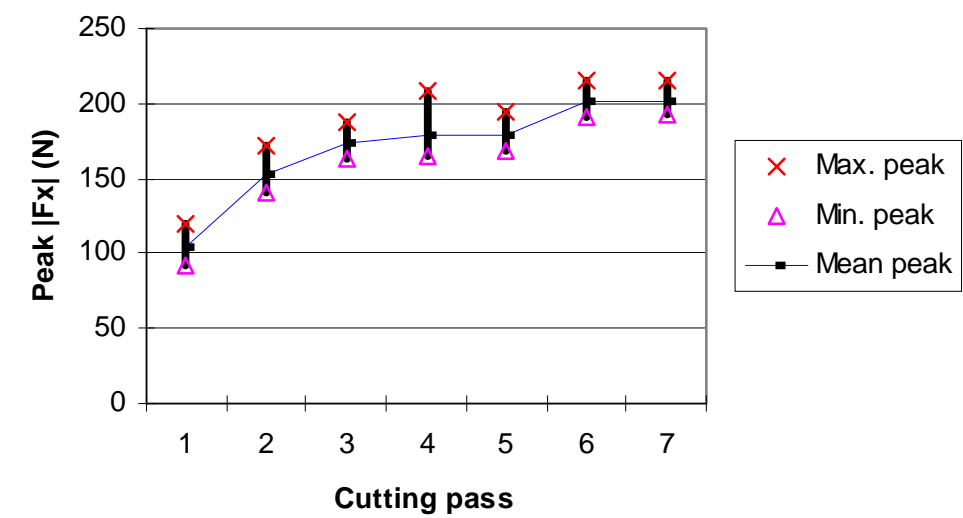

(a)

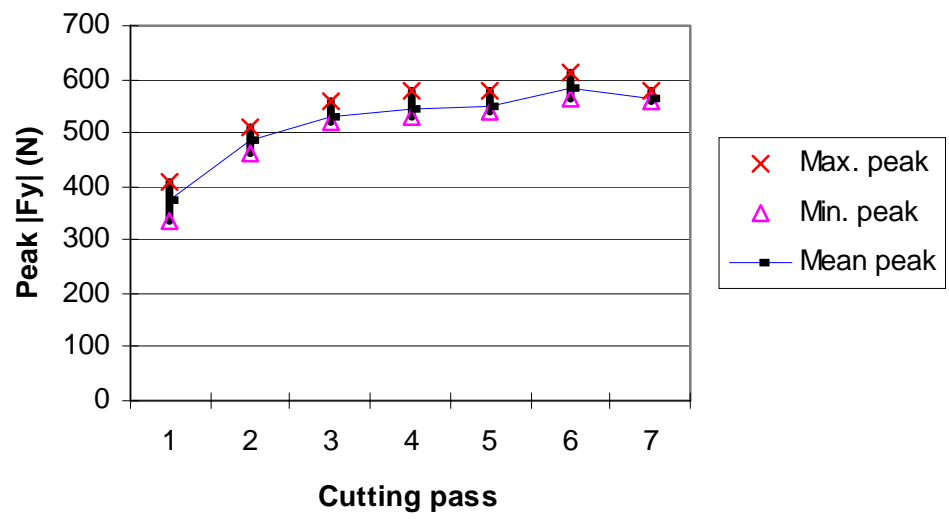

(b)

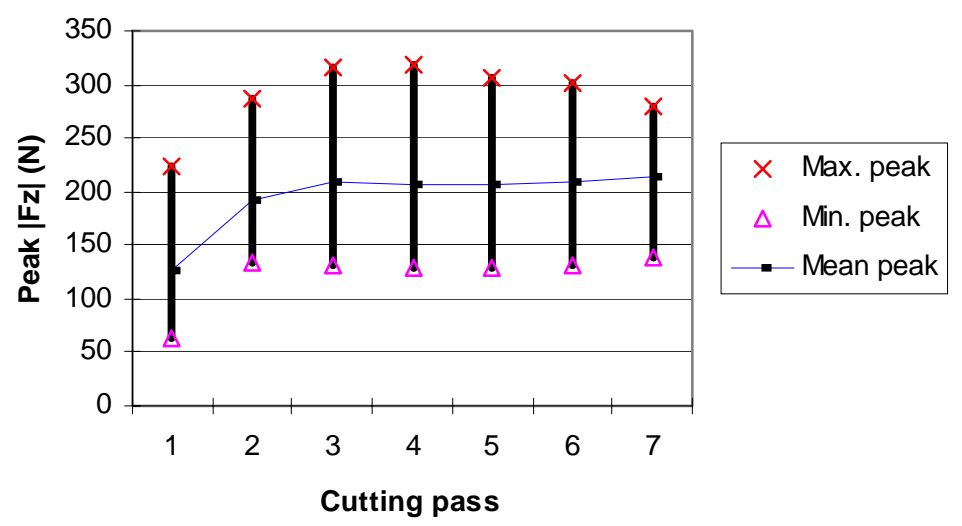

(c)

Figure 19. Variation of peak cutting force in (a). X, (b). Y, and (c). Z directions, down milling, 900 rpm 


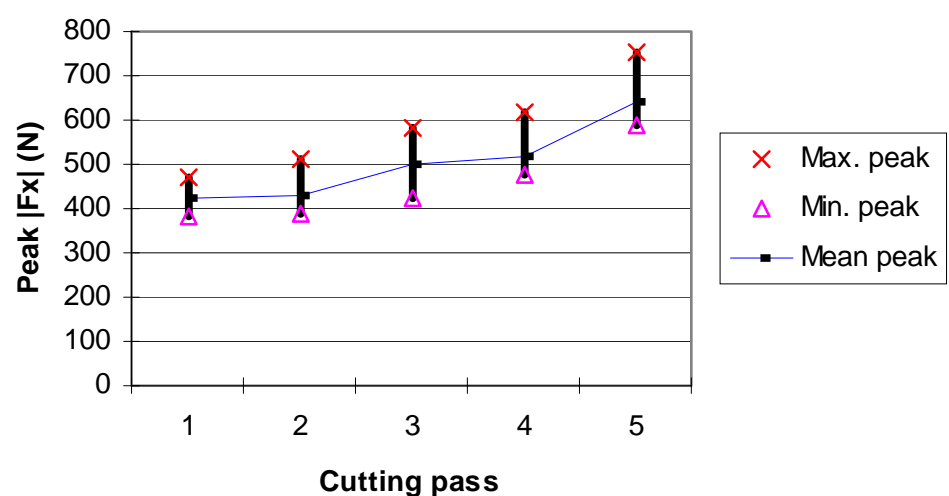

(a)

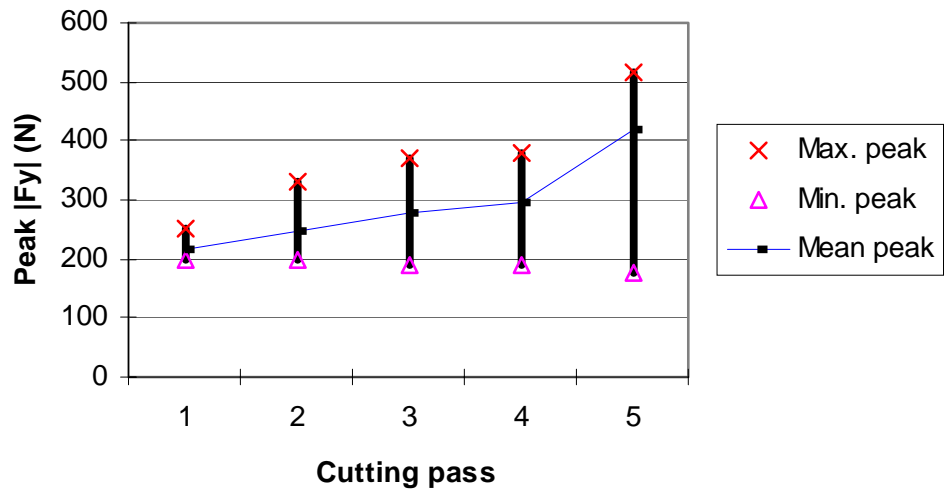

(b)

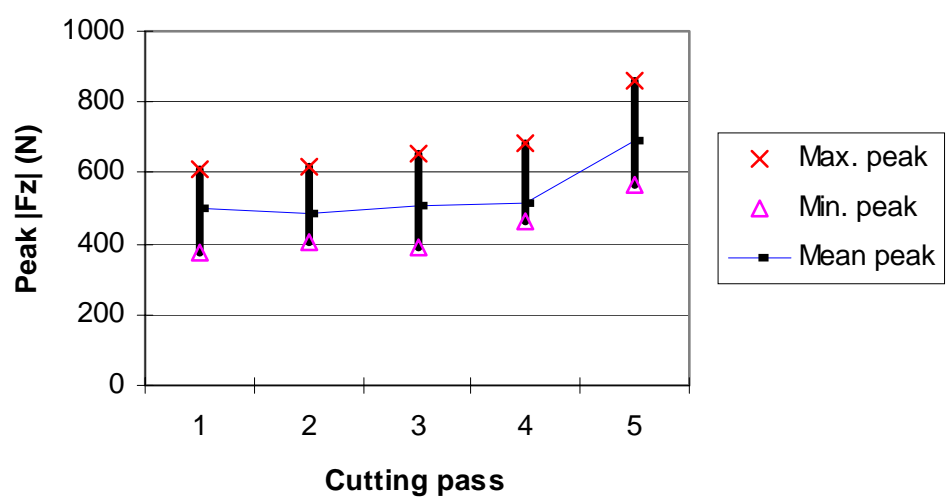

(c)

Figure 20. Variation of peak cutting force in (a). X, (b). Y, and (c). Z directions, up milling, $900 \mathrm{rpm}$ 